\title{
Nanocomposite Reinforcement Effects in Millable Polyurethane Elastomer with Low Content of Halloysite Nanotubes
}

\author{
Chun-Fa OUYANG ${ }^{1, a,{ }^{*}}$, Bing GONG ${ }^{1, b}$, Qun GAO ${ }^{1, c}$ \\ ${ }^{1}$ School of Materials Science and Engineering, Shanghai Institute of Technology, 100 Haiquan Road, \\ Shanghai 201418, China \\ aouyoung_0916@163.com, bgb319611@163.com, ‘wityy@sit.edu.cn \\ ${ }^{*}$ Corresponding author
}

Keywords: Millable Polyurethane, Halloysite Nanotubes, Nanocomposites, Reinforcement.

\begin{abstract}
Millable polyurethane / halloysite nanotubes nanocomposites with high tensile strength and elongation at break were prepared by adding halloysite nanotubes (HNTs) during the preparation of prepolymer. Tensile test revealed that the nanocomposites have both higher tensile strength and elongation at break. In particular, with only $1 \mathrm{wt} \%$ of halloysite nanotubes incorporated, an 1.17-fold increase in tensile strength and 0.58 -fold increase in elongation at break were achieved, respectively. The halloysite nanotube hydroxyl is covalently bonded to the polyurethane molecular chain during the synthesis of the prepolymer, which is involved in the whole reaction, and thus to affect the degree of phase separation and hydrogen bonding between the segments of the polyurethane chain and the halloysite nanotube. In addition, the synthetic polyurethane elastomer nanocomposites owing a linear structure. This paper incorporated HNTs into the synthesis of MPU for the first time to stiffen and strengthen the material at very low loadings. Moreover, an unprecedented environmental no solvent prepolymer method in order to compound MPU / HNTs nanocomposites have been proposed.
\end{abstract}

\section{Introduction}

Polymer nanocomposites reinforced with low fraction of nanoscale fillers containing organic and inorganic have drawn a great deal of attention due to the unique characteristics of nanoparticles, including their large surface area, high surface reactivity, and relative low cost[1,2]. Halloysite nanotubes (HNTs), $\mathrm{Al}_{2} \mathrm{Si}_{2} \mathrm{O}_{5}(\mathrm{OH})_{4} \cdot \mathrm{nH}_{2} \mathrm{O}$, one of naturally occurring clay minerals, is a new kind of prominent nanofillers composed of multi-walled nanotubular-shaped crystalline nanostructures[3]. Generally, HNTs have a $15 \mathrm{~nm}$ lumen with 30-50 nm external diameter and length of around $1 \mathrm{~mm}$. HNTs consist of gibbsite octahedral sheet $(\mathrm{Al}-\mathrm{OH})$ groups on the internal surface and siloxane groups ( $\mathrm{Si}-\mathrm{O}-\mathrm{Si}$ ) on the external surface, which have been successfully applied in the sustained drug and flame retardant release[4,5]. HNTs have been incorporated into polymer matrix as an environmentally benign reinforcing fillers due to their outstanding intrinsic properties such as nanoscale dimensions, high surface area, unique morphology, low density, high specific strength and Young's modulus, and very low coefficient of thermal expansion [6,9].

Castable, millable and thermoplastic are the three primary classes of polyurethane elastomers. Millable polyurethane (MPU) are a special type of synthetic rubber, which is generally compounded by means of conventional rubber processing equipments in the presence of other ingredients / additives. MPU has still an excellent demand in various applications such as footwear, hose and oil field products owing to its high toughness, flexibility, strength, abrasion resistance, and chemical resistance. Many large industrial rolls, copier rolls, O-rings, seals, gaskets and many other mechanical goods requiring abrasion resistance are made using these special elastomers. The basic constituents of polyurethane elastomers are a diisocyanate, a long chain oligomeric polyol, which may be a polyether or polyester oligomer, and low molecular weight diols or diamines as chain extender.

Previously, nanometer-sized materials including graphite oxide nanoplatelets, polyhedral oligomeric silsesquioxane, carbon nanotubes, and layered silicate clays, which own an extremely 
large surface area or a high aspect ratio have been incorporated into castable polyurethane or thermoplastic polyurethane to enhance the mechanical performances and thermal stability.

Although there are many reports in the literature concerning polyurethane nanocomposites, no comprehensive notice has so far been given to the MPU nanocomposites. In the few relevant literature, nanomaterials have been added into MPU which has been purchased in advance only in the later process by mechanical mixing to prepare its nanocomposites.

In the present study, we introduce HNTs which not only have special surface properties (microtubules, easy dispersion), but also have the advantages of wide source and low cost into the synthesis of MPU for the first time to stiffen and strengthen the material at very low loadings. In addition, an unprecedented environmental no solvent prepolymer method in order to compound MPU / HNTs nanocomposites have been proposed.

\section{Experimental Section}

\section{Materials}

4,4'-diphenyl-methane diisocyanate (MDI, TCI), 1,4-butanediol (1,4-BD, Aldrich) and phosphoric acid (98\%, Sinopharm) were used as received. Poly(propylene glycol)(PPG, $\left.\mathrm{M}_{\mathrm{n}}=1000\right)$ were purchased from Shanghai JiaHua Chemical Co., Ltd. (China) and used as received. Halloysite nanotubes, with an outer diameter between $15-100 \mathrm{~nm}$ and approximate length of $500-1000 \mathrm{~nm}$ were purchased from Lingshou Longchuan drilling plugging materials factory (China) without any chemical modification.

\section{Synthesis of Polyurethane Nanocomposite}

The polyether polyurethane prepolymer was synthesized by reacting 4,4'-diphenyl-methane diisocyanate (MDI) (122g) with Poly(propylene glycol) (PPG, $\left.\mathrm{M}_{\mathrm{n}}=1000\right)(165.7 \mathrm{~g})$ and a drop of phosphoric acid in the presence of Halloysite nanotubes at $82^{\circ} \mathrm{C}$ for $3 \mathrm{~h}$. Subsequently, chain extender 1,4-butanediol (1,4-BD) (31.35 g) was dropwise added to the prepolymer and stirred at $50{ }^{\circ} \mathrm{C}$ before casting and curing on a Teflon mold at $120{ }^{\circ} \mathrm{C}$ for $6 \mathrm{~h}$ to obtain a transparent film. The amount of reactive hydroxyl group on halloysite nanotubes was $29 \pm 3 \mathrm{mmol} / \mathrm{g}$ as measured by using titration to determine the excessive isocyanate groups after mixing halloysite nanotubes with known amount of MDI. The molar ratio of MDI to PPG in the prepolymer was 2.85:1, and total $\mathrm{NCO} / \mathrm{OH}$ ratio in the polyurethane was 0.95 . Transparent polyurethane nanocomposite films containing $0.5,1$, and $5 \mathrm{wt} \%$ HNTs were successfully prepared by varying the amount of halloysite and 1,4-butanediol, and coded as MPU / HNT-0.5, MPU / HNT-1, and MPU / HNT-5, respectively. Pure polyurethane films were prepared in the absence of HNTs and coded as MPU. The reaction procedure was shown as follows (Fig.1).

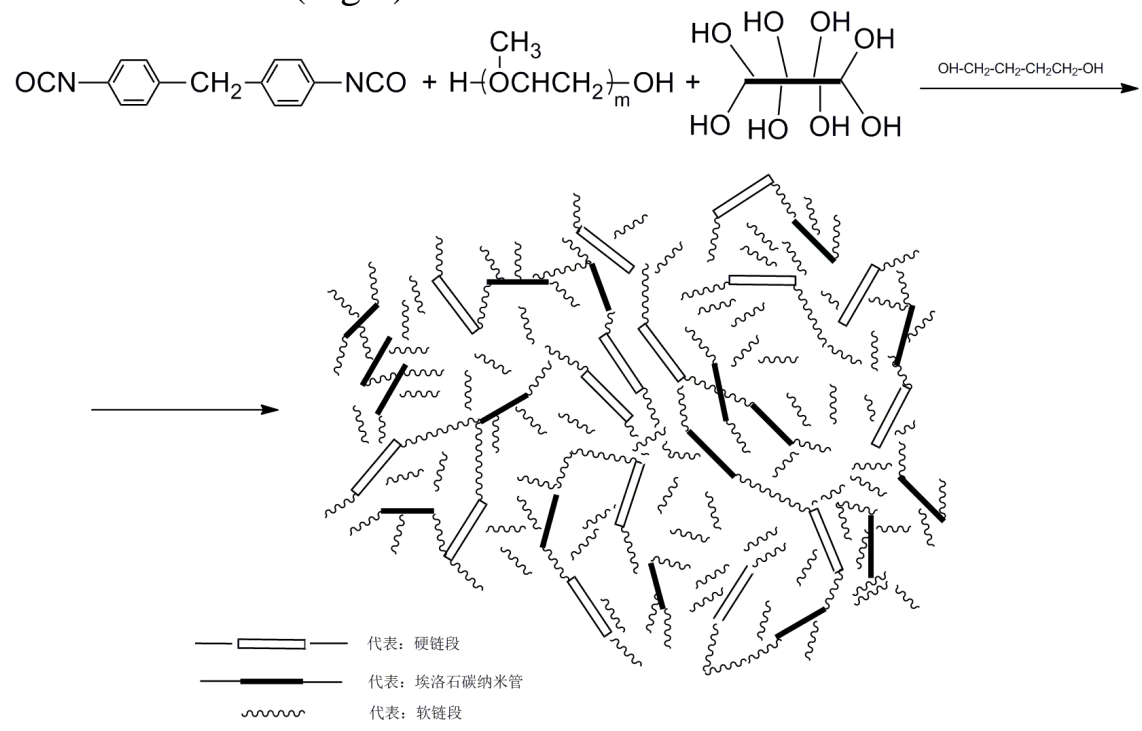

Fig.1 Reaction scheme for the synthesis of elastomeric gum polyurethanes nanocomposites 


\section{Results and Discussion}

FTIR spectra of the pure millable polyurethane showed characteristic bands of urethane stretching $(\mathrm{N}-\mathrm{H})$ at $3280 \mathrm{~cm}^{-1}$, combination of urethane carbonyl $(\mathrm{NH}-\mathrm{CO}-\mathrm{O})$ and esteric carbonyl (CO-O) at $1727 \mathrm{~cm}^{-1}$, combination of $\mathrm{N}-\mathrm{H}$ out-of-plane bending and $\mathrm{C}-\mathrm{N}$ stretching at $1550-1520$ $\mathrm{cm}^{-1}$. In the HNTs, O-H of inner hydroxyl groups and outer surface hydroxyl groups were detected at $3619 \mathrm{~cm}^{-1}$ and $3695 \mathrm{~cm}^{-1}$, respectively. The infrared spectrum shows absorption bands around $1034 \mathrm{~cm}^{-1}$ and $910 \mathrm{~cm}^{-1}$, which are attributed to the Si-O stretching vibrations and $\mathrm{Al}-\mathrm{OH}$ vibrations bands, respectively.

For all the spectra of nanocomposites as shown in Fig.2, the intensity of the absorption near 3695 $\mathrm{cm}^{-1}$ and $3619 \mathrm{~cm}^{-1}$ greatly decreased, which due to the reaction of the hydroxyl group of HNTs with MDI. Similarly, the band of -NCO group was not detectde at $2300-2200 \mathrm{~cm}^{-1}$ in the products as a result of complete reaction. Si-O-C stretching vibration absorption peak was detected at 1104 $\mathrm{cm}^{-1}$ and $1025 \mathrm{~cm}^{-1}$ (coinciding with C-O-C symmetric vibration absorption peaks), which confirmed the reaction of the hydroxyl group of HNTs with the $-\mathrm{N}=\mathrm{C}=\mathrm{O}$ of MPU prepolymer and thus generated these MPU / HNTs nanocomposites. The carbonyl absorption band splits into two peaks, $1704 \mathrm{~cm}^{-1}$ and $1727 \mathrm{~cm}^{-1}$, corresponding to hydrogen-bonded and free carbonyl groups, respectively. The carbonyl hydrogen-bonding index, i.e., the intensity ratio of the hydrogen-bonded carbonyl peak to the free carbonyl peak, decreased with the introducing of HNTs. The HNTs were covalently bonded to the polyurethane molecular chains during the synthesis of prepolymer, which may affect the hydrogen bonding and phase separation of the segmented polyether-polyurethane. In the hard segment, the hydrogen atoms of N-H groups serve as proton donors and the urethane carbonyl groups serve as proton acceptors.

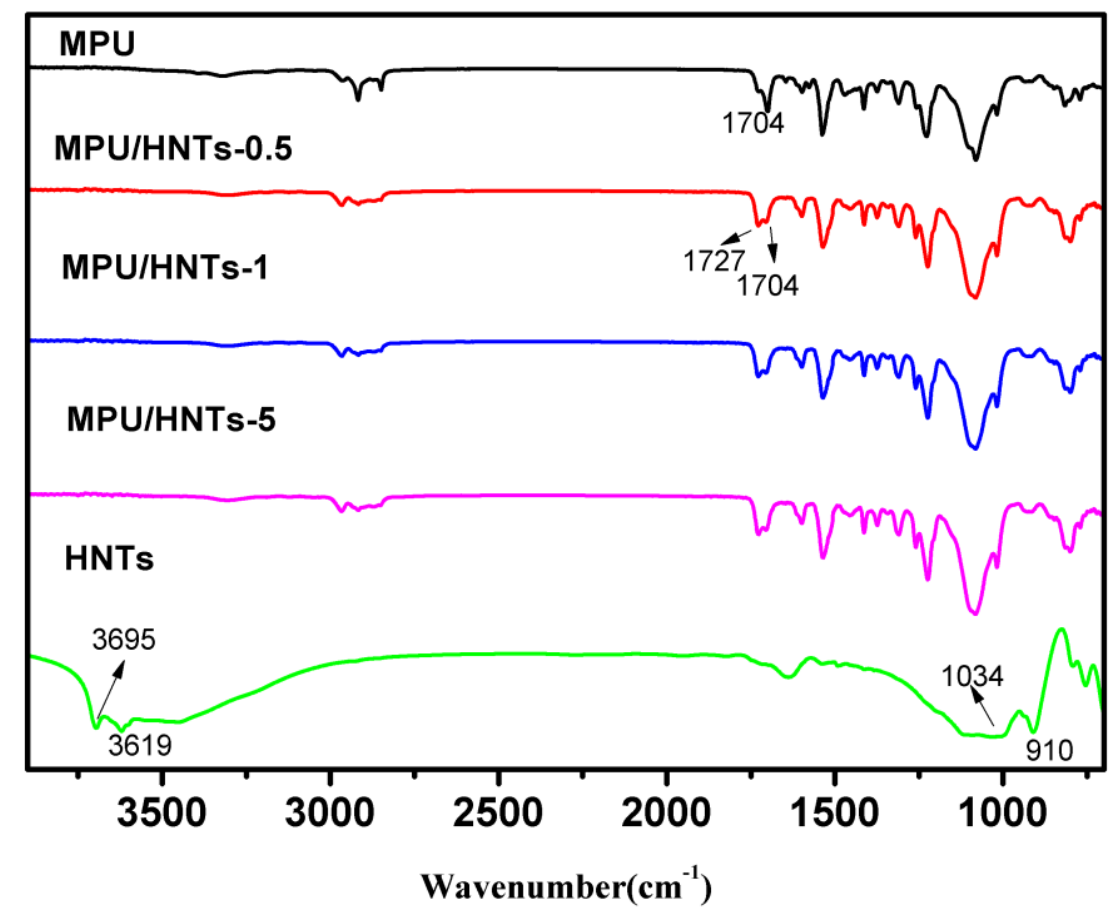

Fig.2 FTIR spectra of halloysite nanotubes (HNTs), pure millable polyurethane (MPU), PU / HNTs nanocomposites

The X-ray diffraction (XRD) spectra of HNTs, pure MPU, and the MPU / HNTs, nanocomposites are presented in Fig.3. The $2 \theta$ angle at $20.09^{\circ}$ corresponds to the amorphous diffraction peak of pure MPU, which shows relatively blunt shape, and indicates low degree of crystallinity of the sample. The $2 \theta$ angle at $12^{\circ}$ corresponds to the HNTs. The obvious diffraction peak of HNTs was visible duing to the crystalline structure of a typical silicate materials. Because of the low content of HNTs, changes of the peak shape with broadening width around $2 \theta$ angle at $20^{\circ}$ were visible in 
MPU / HNTs-0.5 and MPU / HNTs-1, which was due to the reaction of the hydroxyl group of HNTs with the $-\mathrm{N}=\mathrm{C}=\mathrm{O}$ of MPU. These indicate that the original nanotube structure of halloysite was well preserved in the nanocomposites. Such preferential allocation further implies the incorporation of HNTs into the hard segment domains of MPU that is consistent with the result of FTIR analysis.

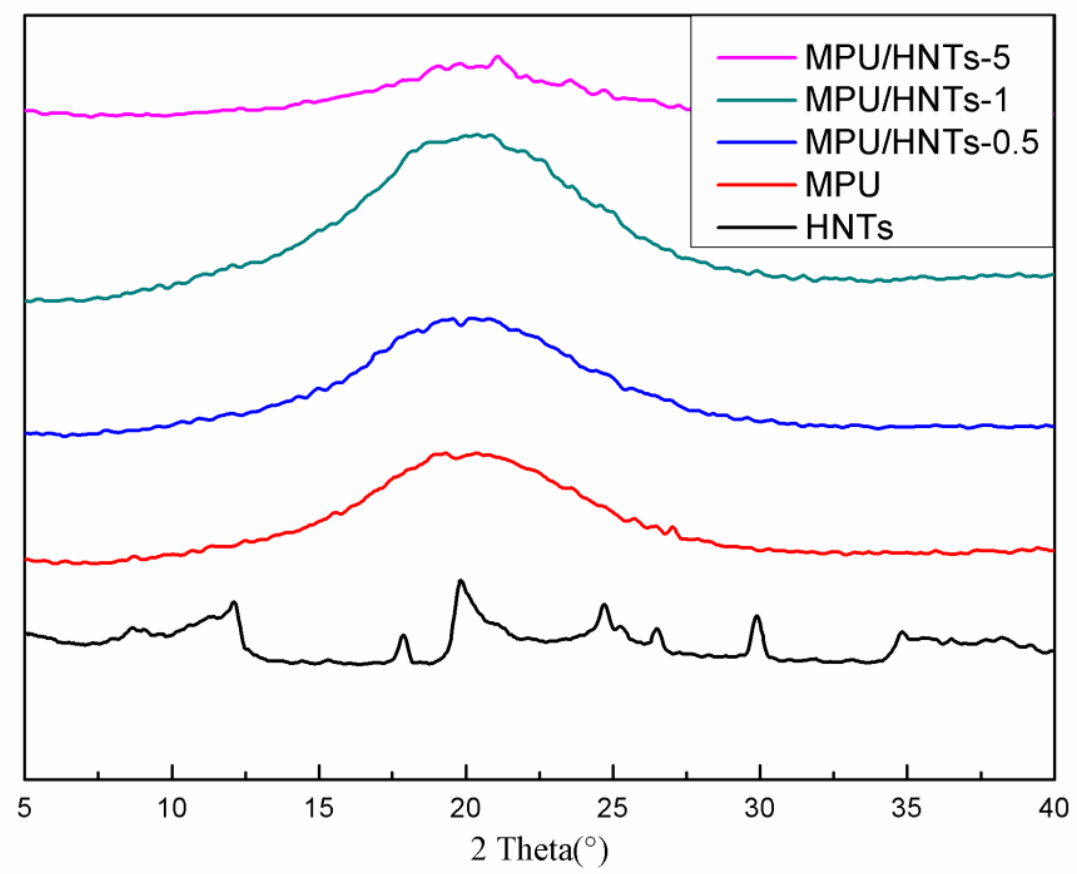

Fig.3 XRD pattern of HNTs, MPU, and MPU / HNTs nanocomposites.

The phase separation of MPU resulting from thermodynamic incompatibility between the soft and hard segments plays a key role in the physical properties. The glass transition temperature $\left(\mathrm{T}_{\mathrm{g}}\right)$ of soft segment molecular chains will shift to higher temperature when the compatibility between soft segment and hard segment increases and the micro-phase separation degree decreases. Thus, the phase separation degree of materials can be determined according to the movement about $\mathrm{T}_{\mathrm{g}}$ of soft segment molecular chains. Damping factor $\tan \delta$ of the samples as a function of temperature are expressed in Fig.4. The influence of HNTs on the phase separation structure was also featured by the increase of $T_{g}$ of the nanocomposites. The increase of $T_{g}$ for the nanocomposites is due to the fact that the HNTs are intensely associated with the hard segment of MPU, resulting in lower fraction of hydrogen bonded carbonyl groups in the hard segment and an decrease of the degree of freedom for the soft segment in nanocomposites. The height and sharpness of the damping peaks indicate the degree of order and the freedom of motion of the molecules in the soft domains. The amplitude of the damping peak corresponding to the glass transition of the products increased after incorporating HNTs, which could be attributed to the greatly restricted motion of MPU chains resulting from the covalent bonding and cross-linking between MPU molecules and HNTs. The flexible of soft segment polyurethane matrix shift to weaker. The result is consistent with the result of FTIR and XRD analysis.

The introduction of HNTs as the reinforcing filler in MPU led to improvement of tensile strength, elongation at break of the nanocomposites as summarized in Tab.1. The tensile strength was increased from 11.04 MPa for pure MPU to 23.94 MPa for MPU / HNT-0.5, and further to 24.01 MPa for MPU / HNT-1 containing only $1 \mathrm{wt} \%$ HNTs. Analogously, the elongation at break was increased from $273.88 \%$ for pure MPU to $388.55 \%$ for MPU / HNT-0.5, and further to $431.72 \%$ for MPU / HNT-1 containing only $1 \mathrm{wt} \%$ HNTs. To our knowledge, this is the first time such enhancement in mechanical properties is achieved with only $1 \mathrm{wt} \%$ of nanoscale HNTs reinforcement of the raw rubbery matrix. 


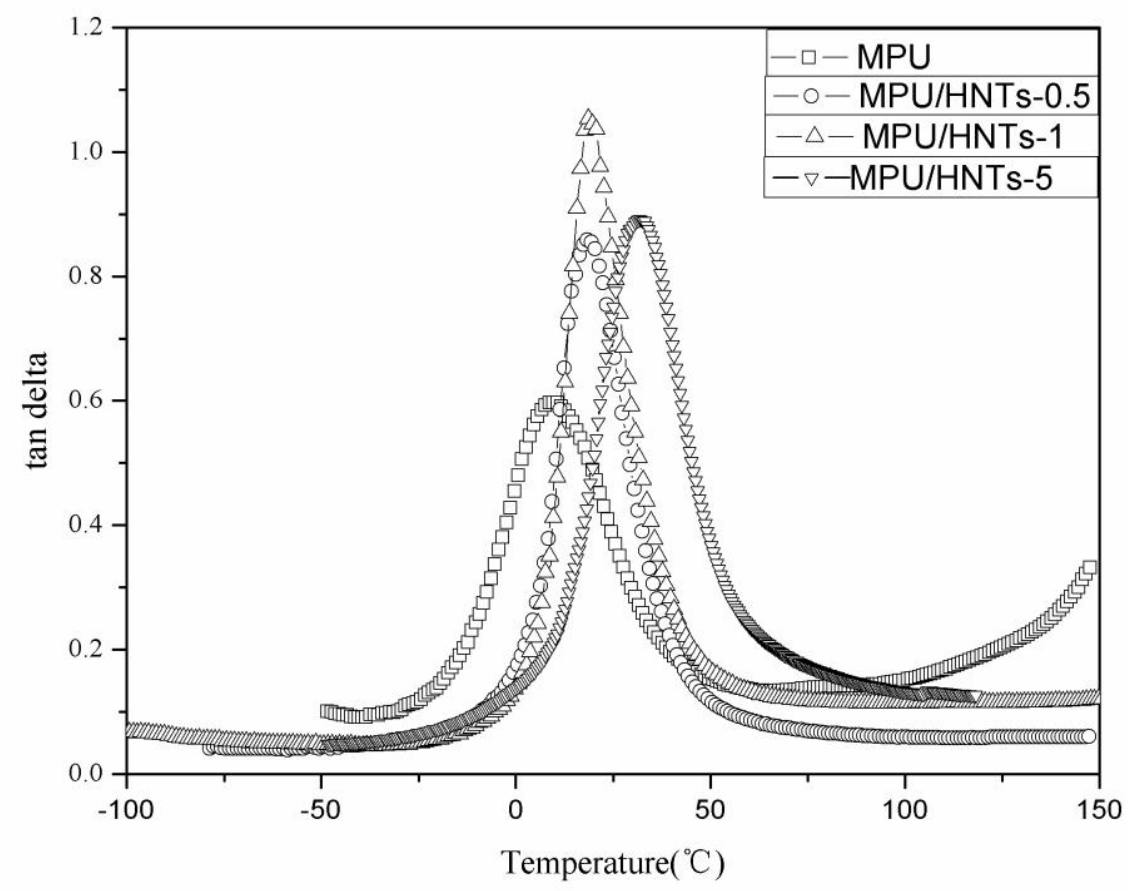

Fig.4 Damping factor tan $\delta$ of the MPU and MPU / HNTs nanocomposites as a function of temperature

Tab.1 Physical and mechanical properties of MPU and MPU / HNTs Nanocomposites

\begin{tabular}{|c|c|c|c|c|}
\hline Samples & $\begin{array}{c}\text { Tensile } \\
\text { strength } \\
{[\mathrm{MPa}]}\end{array}$ & $\begin{array}{c}\text { Elongation } \\
\text { at break } \\
{[\%]}\end{array}$ & $\begin{array}{c}\text { Young's } \\
\text { Modulus } \\
{[\mathrm{MPa}]}\end{array}$ & $\begin{array}{c}\text { Hardness } \\
{[\text { Shore A] }}\end{array}$ \\
\hline MPU & 11.04 & 273.88 & 13.49 & 85 \\
\hline MPU / HNT-0.5 & 23.94 & 388.55 & 12.77 & 82 \\
\hline MPU / HNT-1 & 24.01 & 431.72 & 12.79 & 84 \\
\hline MPU / HNT-5 & 10.91 & 364.42 & 6.22 & 89 \\
\hline
\end{tabular}

\section{Conclusions}

In conclusion, we have confirmed the synthesis of high tensile strength and elongation at break millable polyurethane nanocomposites by adding very low amount of halloysite nanotubes as the reinforcing filler. The individualized halloysite nanotubes were covalently bonded with the hard microdomains of segmented polyether polyurethane, which may affect the phase separation of the nanocomposites, and such nanostructure is crucial to stiffen and toughen the millable polyurethane without reducing its extensibility. With the addition of only $1 \mathrm{wt} \%$ halloysite nanotubes, we received millable polyurethane nanocomposite with tensile strength of $24.01 \mathrm{MPa}$, elongation at break of $431.72 \%$, which surpass those of conventional raw rubbery materials. Certainly, the mixing process through adding reinforcing agents such as carbon black, stearic acid or using different cure systems in the later can be carried out to further enhance our synthetic nanocomposites performance and reduce costs. Our investigation have created strong halloysite nanotubes - millable polyurethane interaction at the interface since the dissociation and dispersion of structural unit in HNTs was easily achieved under mechanical shear stress. The results of this literature will attract huge attention on widening the practical use and applications of halloysite nanotubes-based polymer nanocomposite materials. 


\section{References}

[1]R. S. Sinha, M. Okamoto. Polymer/layered silicate nanocomposites: a review from preparation to processing, J. Prog Polym Sci. 28 (2003)1539-1641.

[2]L. Jia, C. Zheng. Simultaneous reinforcement and toughening of polyurethane composites with carbon nanotube/halloysite nanotube hybrids, J. Composites Science and Technology. 91 (2014) 98-103.

[3]W. Yah, A. Takahara, Y. M. Lvov. Selective modification of halloysite lumen with octadecylphosphonic acid: new inorganic tubular micelle, J. J Am Chem Soc, 134 (2012) 1853-1859.

[4]H. Jing, Y. Higaki, W. Ma, H. Wu, W. Yah , H. Otsuka, et al. Internally modified halloysite nanotubes as inorganic nanocontainers fora flame retardant, J. Chem Lett, 42 (2013) 121-123.

[5]H. Ismail, S.Z. Salleh, Z. Ahmad. Properties of halloysite nanotubes-filled natural rubber prepared using different mixing methods, J. Materials and Design, 50 (2013) 790-797.

[6]D. Tao, Y. J. Higaki, W. Ma, et al. Chain orientation in poly(glycolic acid)/halloysite nanotube hybrid electrospun fibers, J. Polymer, 60 (2015) 284-291.

[7]M. X. Liu, Z. X. Jia, D. M. Jia, C. R. Zhou. Recent advance in research on halloysite nanotubes-polymer nanocomposite, J. Progress in Polymer Science, 39 (2014) 1498-1525.

[8]L. Jiang, C. Zhang, M.K. Liu, Z. Yang, W. W. Tjiu, T. X. Liu. Simultaneous reinforcement and toughening of polyurethane composites with carbon nanotube/halloysite nanotube hybrids, J. Composites Science and Technology, 91 (2014) 98-103.

[9]B. Lecouvet, M. Sclavons, S. Bourbigot, J. Devaux, C. Bailly. Water-assisted extrusion as a novel processing route to prepare polypropylene/halloysite nanotube nanocomposites: Structure and properties, J. Polymer, 52 (2011) 4284-4295. 